\title{
Laparoscopic Management of Ovarian Cysts in Pregnancy: Study of Surgical Outcome and Obstetric Outcome.
}

\author{
Dr Vijaykumar Koravi ${ }^{1}$, Dr Vijaykumar C R ${ }^{2}$, Dr Chaitra Lingappa ${ }^{3}$ \\ ${ }^{1}$ Senior Resident, Dr.B.R.AMC\&H \\ ${ }^{2}$ Associate Professor, Dr.B.R.AMC\& $H$ \\ ${ }^{3}$ Post graduate, $\operatorname{Dr} B . R . A M C \& H$
}

\begin{abstract}
:
Objective: Laparoscopic approach for ovarian cysts during pregnancy would be a better method for a good obstetric outcome.
\end{abstract}

Design: The following study is a prospective analysis of surgical and obstetric outcome among five pregnant women with incidental ovarian cysts during $2^{\text {nd }}$ trimester.

Subjects: Five ANC patients who presented with vague symptoms to emergency department who were diagnosed with ovarian cysts in pregnancy.

Intervention: These antenatal mothers with ovarian cyst presented themselves with vague symptoms and were admitted to our hospital, following which, symptomatic treatment was given . they were been explained about the problem, need for surgical intervention and an informed consent been taken. For patients willing, Laparoscopic cystectomy was done as surgical intervention and patient been discharged after 3 days (post operative care). These antenatal mothers were been followed up till delivery and outcome noted.

Results: Amongst 5 cases, 3 patients presented with acute abdomen and 2 patients presented with pessure symptoms like, acute urinary retention, increased frequency of micturition. The size of cysts were between 12-24 gravid uterus size, with diagnosis of simple clear cysts in 3 cases, dermoid cyst in 1 case and haemorrhagic cyst in another case. Options were given between exploratory laparotomy and laparoscopic surgery about pros and cons. Patient who gave consent for the laparoscopic surgery were included in the study.Amongst 5 patients , 3 were operated under general anesthesia and 2 under Spinal Anaesthesia, Without trendelenburg position.

Mean blood loss was about $<100 \mathrm{cc}$. Average operating time was 40 minutes. There was no miscarriages amongst the study group. 1 patient had pre-term vaginal delivery, 1 patient underwent caesarean section, and rest had spontaneous uneventful normal vaginal delivery and no any gross abnormality.

\section{Introduction}

Adnexal masses during pregnancy are not uncommon. The incidence of adnexal masses during pregnancy is estimated to be $0.2-2 \%$ depending on the stage of pregnancy . With 1-6\% malignancy rates, the vast majority of these masses are benign. ${ }^{1}$ Study on epidemiology reveals that the incidence of all types of ovarian cysts during pregnancy is about one out of 600 .

The frequency of ovarian tumors is about 1 in 1000 pregnancies ${ }^{3}$ Most of the cases are benign cysts out of which mature cystic teratoma accounts for $50 \%$ of the cases, followed by benign cyst adenomas(20\%), functional cysts $(13 \%)$ and ovarian cancer $(0.6 \%)$, while symptomatic ovarian tumors which are associated with pregnancy ranges from 1:8-1:2328 .

Before the incorporation of ultrasound into clinical practice, ovarian cysts during pregnancy were mainly diagnosed by physical examination when women presented with symptoms including abdomino- pelvic pains or a palpable mass. Ovarian cysts with diameter $>6 \mathrm{~cm}$ which persist or enlarge beyond 16 weeks gestation, are at risk of complications and need tissue diagnosis and therefore surgical evaluation. ${ }^{5}$

\section{Results}

This is A Prospective Study at Dr. B.R. Ambedkar Medical College and Hospital, Bangalore.

5 antenatal patients with symptomatic ovarian cysts were included in our study during Sept 2014 to May 2016. Different ranges of sizes of ovarian cyst have come across in our study of largest size of cyst being $=20 \times 1 \mathrm{cms}$. All 5 patients presented during $2^{\text {nd }}$ trimester of pregnancy. 3 patients $(60 \%)$ presented to the emergency department with acute abdomen and rest 2 patients (40\%) presented with chronic abdominal pain.

2 were primigravidae (40\%) and 3(60\%) multigravidae with age being between 19-32 years. 1 patient $(20 \%)$ in our study had previous caesarean section among 3 multigravidae. Clear cysts was the ultrasonological findings in 3 patients ( $60 \%$ ) and haemoerhagic cyst in 1 patient ( $20 \%$ ) and dermoid cyst in another $(20 \%)$. 
Laparoscopic Management of Ovarian Cysts in Pregnancy: Study of Surgical Outcome and ...

Table 1:

\begin{tabular}{|c|c|c|c|c|c|}
\hline Criteria & $I^{\prime \prime}$ case & $2^{n d}$ case & $y^{2}$ case & $f^{f}$ case & $5^{\text {th }}$ case \\
\hline Patient Age & $22 \mathrm{yr}$ & $19 \mathrm{yrs}$ & $24 \mathrm{yrs}$ & $26 \mathrm{yrs}$ & $32 \mathrm{yrs}$ \\
\hline Parity & $\mathrm{G}_{2} \mathrm{~A}_{1}$ & $\mathrm{G}_{1}$ & G.P. $P_{i} L_{1}$ & $\mathrm{G}_{2} \mathrm{P}_{1} \mathrm{~L}_{\mathrm{i}} \mathrm{A}_{1}$ & G., $P_{1} L_{4}$ \\
\hline Gestational age at Operation & $23 \mathrm{wks}$ & $26 \mathrm{wks}$ & $20 \mathrm{wks}$ & $22 \mathrm{wks}$ & $22 \mathrm{wks}$ \\
\hline Previous Surgery & Nil & $\mathrm{NaI}$ & PrevLSCS & Nil & Nil \\
\hline Presenting Features & Acute Abdomen & Acute Abdomen & Chronic abdomen pain & Acute abdomen & Chronic abdomen pain \\
\hline Scan findings & Clear Cyst & Clear Cyst & Demaid cyst & Haemorthagic Cyst & Clear cyst \\
\hline Cysts size at operation(approximate) & $20 \times 18 \mathrm{cms}$ & $15 \mathrm{x} 12 \mathrm{cms}$ & $6 \times 5 \mathrm{cms}$ & $4 \mathrm{x} 4 \mathrm{cms}$ & $10 \mathrm{~s} 8 \mathrm{cms}$ \\
\hline POD Collection & Nil & Nil & minimal & Nil & Nil \\
\hline CA125lenel & 22 & 19 & 21 & 12 & 17 \\
\hline
\end{tabular}

Table 2:

\begin{tabular}{|l|l|l|l|l|l|}
\hline Category & $\mathbf{1}^{\text {st }}$ case & $\mathbf{2}^{\text {nd }}$ case & $\mathbf{3}^{\text {rd }}$ case & $\mathbf{4}^{\text {th }}$ case & $\mathbf{5}^{\text {th }}$ case \\
\hline Anesthesia & SA & SA & GA & GA & GA \\
\hline Per abdomen Size & $28 \mathrm{wks}$ & $30 \mathrm{wks}$ & $24 \mathrm{wks}$ & $22 \mathrm{wks}$ & $26 \mathrm{wks}$ \\
\hline Uterus size & $22 \mathrm{wks}$ & $24 \mathrm{wks}$ & $20 \mathrm{wks}$ & $18 \mathrm{wks}$ & $24 \mathrm{wks}$ \\
\hline Ovarian cyst size & $18 \times 16 \times 14 \mathrm{cms}$ & $15 \times 10 \times 12 \mathrm{cms}$ & $6 \times 5 \times 4 \mathrm{cms}$ & $4 \times 4 \times 3 \mathrm{cms}$ & $10 \times 8 \times 6 \mathrm{cms}$ \\
\hline Adhesions & nil & Nil & Minimal & Nil & Nil \\
\hline Injuries to Adjacent Structures & nil & Nil & Nil & Nil & Nil \\
\hline Blood loss & $<30 \mathrm{ml}$ & $<20 \mathrm{ml}$ & $<20 \mathrm{ml}$ & $<20 \mathrm{ml}$ & $<30 \mathrm{ml}$ \\
\hline Spillage & nil & Nil & Nil & Nil & Nil \\
\hline
\end{tabular}

All patients were investigated with CA 125 levels and were within nomal limits (ranging from 12-22). 4 of our patients were given tocolytics for 24 hours post op and hospital stay for 5 days on an average.

The antenatal follow up was been done regularly as patients were very co operative and followed our advice for attending antenatal clinic regularly and hence not a cumbersome for us to follow them up.

Though, out of curiosity and anxiety of ours vigorous monitoring and follow up of antenatal patients were done, the outcome in terms of maternal and fetal outcome was good.

Out of , 1 patient (20\%) underwent LSCS Ilvlo previous LSCS in labour, rest 4 patients (80\%) had vaginal delivery. Out of 4 patients who had vaginal delivery, 1 patient $(25 \%)$ had preterm vaginal delivery.

Fetal outcome was measured by apgar score of which all 5 babies had a good apgar score and good fetal outcome.

Table 3:

\begin{tabular}{|l|l|l|l|l|l|}
\hline Criteria & $1^{\text {st }}$ case & $2^{\text {nd }}$ case & $3^{\text {rd }}$ case & 4th case & $5^{\text {th }}$ case \\
\hline Tocolytics & Given & Given & Given & Not Given & Given \\
\hline Hospital stay & 5 days & 5 days & 5 days & 4 days & 5 days \\
\hline Miscarriage/ Preterm labour & Pre term labour & Nil & Nil & Nil & nil \\
\hline Delivery & Pre term labour & TVD & LSCS & TVD & TVD \\
\hline Apgar Score 1/5m & $8 / 10$ & $9 / 10$ & $8 / 10$ & $9 / 10$ & $9 / 10$ \\
\hline
\end{tabular}

TVD- term vaginal delivery

\section{Discussion}

Ovarian cysts were more likely to be surgically removed to resolve symptoms, avoid complications or because of the malignant potential.

Since the finding of a ovarian cysts during pregnancy now is mainly incidental, accurate diagnosis is important to identify those patients who are in need of surgery. 6

Ovarian cysts in pregnany are now relatively better appreciated due to the advent and access of high resolution Trans Vaginal Ultrasound.

Majority of ovarian cysts are asymptomatic and spontaneously resolve prior to 16th week of gestation. While few remain persistent, painful and progressive ovarian cysts imparts dilemma in the management as they can cause complications for the mother and fetus.

The appreciated choice of treatment is still in controversy for the asymptomatic ovarian masses in pregnancy.7

The high sensitivity and specificity of ultrasonography to characterize the morphology of pelvic masses make it an ideal tool to use as a first choice diagnostic tool since morphology is the most important determinant in distinguishing benign masses from malignancies.8

Most surgical options for ovarian cysts in pregnancy are managed ideally in the second trimester after organogenesis is complete decreasing the risk of fetal loss, eliminating the $15 \%$ to $20 \%$ background risk of spontaneous miscarriage and allowing for spontaneous regression of the mass. 9

Due to the anatomical, hormonal and vascular charges, a higher incidence of torsion (7.0-28.0\%) rupture (1.3$3.7 \%$ )and infection (1.2-2.4\%)of ovarian cysts has been reported in pregnant patients. 10

The conservative management usually refers to serial clinical features monitoring with repeated ultrasonographic measurement.11 
CA125 testing routinely not done. Though MRI is preferable to CT scanning, but both modalities should be avoided in the first trimester.12

Once the decision is made for surgical management, the specific approach is the next consideration.

Until recently, most of these procedure were performed by exploratory laparotomy and do not differ with regard to fetal outcome that is, fetal weight, gestational age, growth restriction infant survival rate and fetal malformations. 13

Now questions arise about the anesthetic complications and intra operative injuries based on increased size of gravid uterus, Trendelenburg position, the compromised diaphragmatic excursion after pneumo -peritoneum and carbon dioxide toxemia.

With availability of modern non teratogenic anesthesia ,acceptable intra abdominal pressure selection (10-12 $\mathrm{mmHg}$ )and optimal trendelenburg position, the laparoscopic procedure in pregnancy especially in 2nd trimester is a safe procedure and less cumbersome with experienced team.

The possible risks of laparoscopy include compression of uterine blood flow through elevated intra -abdominal pressure, fetal acidosis, fetal exposure to carbon monoxide from coagulation etc.

Due to restricted space available, as the gravid uterus and bowel loops encroaches over surgical field chances of uterine injury during port placement, Injury to adjacent vital organs, etc may not be under weighed.

The risks of hypercarbia and acidosis are reduced by keeping the operating time short and pressures as low as possible - not higher than $15 \mathrm{mmHg}$. Ventilation of the lungs needs to be carefully monitored and constantly adjusted to compensate for the pneumoperitoneum and positional changes. 14

\section{Conclusion}

The incidence of ovarian cysts in pregnancy are on rise. With the judicious and apt laparoscopy techniques used during dealing of surgeries in pregnancy, the outcome is heralded to be better. Hence laparoscopic ovarian cystectomy in pregnancy can be embedded amongst the options of surgical interventions and gives good surgical and obstetric outcome.

\section{References}

[1]. Hoover and jerkins, 2011; lieseroueitz, 2006; runowiez and brawer, 2014; [telischaket al, 2008]

[2]. Management of ovarian cysts in pregnancy; a care report, journal title European journal of gynecological oncology [EUR.J.GYNAECOL.ONCOL.] ISSN 0392-2936_2005,VOL.26, N0.6, PP.651-653.

[3]. Hermans RHM , Fischer DC, Van der Putten HWHM; Adnexal masses in preganancy2003, 26:167-172.

[4]. Ultra sound review of obstetrics and gynecology [NLM - MEDICINE] Jul. 1 2004,vol.24, ISS 1; pg. 622

[5]. Al-Fozan H, Tulandi T : Safety and risks of laparosopy in pregnancy. Obstet Gynecol 2002, 14(4):375 - 379.

[6]. Bernhard etal, 1999; glance etal; 2008,leiserocuity, 2006]

[7]. European journal of obstetrics and gynecology and reproductive biology, volume 82, issue 1, 18 January, pages 5-99

[8]. Usui et al.,2000; Telischak et al.,2008:hooover and Jenkins,2011:Cohen-Herriou et al.,2013:Levine,2014.

[9]. Fawzia Sanaullah, Ashwini K Trehan, Ovarian cyst impacted in the pouch of douglas at 20 weeks'

[10]. R Behera . Symptomatic ovarian cyst in pregnancy- Laparoscopic assisted ovarian cystectomy- An Alternative , Qualitative, Feasible, Safe option vol 16

[11]. A Prospective study of the role of ultrasound in the management of adnexal masses in pregnancy BJOG:Gerado Zanetta , Eloisa Mariani, Vol 110, 2003, 578-583

[12]. Deborah N . Platek, MD, $15^{\text {th }}$ annual meeting of society of Perinatal Obstetricians , Atlanta , 1995, 23-28

[13]. Laparoscopic management of adnexal masses, Safety and effectiveness. J Reprod Med 2002, 47(I):50-59.

[14]. Yuen PM ,Ng PS, Outcome in laparoscopic management of persistent adnexal mass during the second trimester of pregnancy.2004, 18(9):1354-1357. 